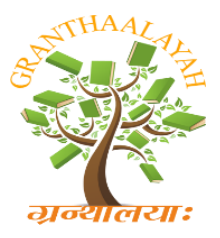

INTERNATIONAL JOURNAL OF RESEARCH GRANTHAALAYAH

A knowledge Repository

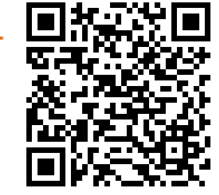

\title{
PAINT POLLUTION HARMFUL EFFECTS ON ENVIRONMENT
}

\author{
Tina Porwal
}

M.L.B. Girls P.G. College, Indore, (M.P.)

\begin{abstract}
Every year we like to paint our home, furniture, etc. for decoration, protection, identification, sanitation. But we forget the impact of paint on our environment. This can cause some serious hazardous effect on our body like headaches, trigger allergies, asthmatic reactions, irritate skin, eyes, and put increased stress on vital organs such as the heart and not only paint but also its byproduct or by which paint creates are also more dangerous to us and our environment.
\end{abstract}

Keywords:

Paint, Environment, Pollution, VOCs, Pigments.

\section{INTRODUCTION}

Paint generally include pigment (the colour), carried by a resin and/or binder, a solvent to help the paint application, and a dryer. In vinyl and acrylic paints they will also include plastics compounds. Some will include formaldehyde, arsenic, thinners, and foamers.

Paint typically consists of pigment, resin, solvent and additives:

- Pigment-to provide colour, hiding and control gloss. Pigments are usually divided into two groups. One called 'Prime Pigments' includes pigments such as Titanium Dioxide (white), Chrome Green Oxide, Yellow and Red Iron Oxides, etc. The other group of pigments is called 'Extender Pigments' and includes Calcite (Calcium Carbonate), Talc (Magnesium Silicate), Mica, Barytes (Barium Sulphate), etc.

- Resin - the binder to hold the pigment particles together and provide adhesion to the surface painted. Waterborne paints most often use acrylic emulsion polymers as binders. These come in a wide variety of types and combinations. Common acrylic polymer types are based on monomers such as methyl methacrylate and butyl methacrylate. Traditionally, lower cost paints have been formulated on PVA (Poly Vinyl Acetate) binders. Solventbased resins come in a very wide range of types. The most common solvent based resins are termed 'alkyd resins' that are normally used in enamel paints. Urethane alkyds often used in clear varnishes. Protective coating resins include types such as Epoxy, Urethane, Polysiloxane and Moisture Cured Urethane.

- Solvent - to act as a carrier for the pigments and resin - the solvent may be organic (such as Mineral Turps) or water.

- Additives - to enhance certain properties such as ease of brushing, mould resistance, scuff resistance, drying and sag resistance. 
Paint is more than just the colour though; it is a material that is applied as a liquid and dries by a variety of chemical processes to a solid.

We apply paint for:

- Decoration

- Protection

- Identification

- Sanitation

\section{HARMFUL EFFECTS OF PAINT POLLUTION}

Prolonged or high exposure to paint and paint fumes can cause headaches, trigger allergies and asthmatic reactions, irritate skin, eyes and airways, and put increased stress on vital organs such as the heart.

The World Health Organization (WHO) has reported a 20\%-40\% increased risk of certain types of cancer (in particular lung cancer) for those who come into regular contact with, or work with paint while Danish researchers point to the added possibility of neurological damage.

By far, the most important environmental impact from paints is the release of volatile organic compounds (VOCs) during the drying process after the coating is applied. Virtually everything but the solids in a typical paint formulation is released to the air.

Once in the atmosphere, VOCs participate in the formation of ozone. In the presence of nitrogen oxides (NOx) and sunlight, VOCs react with oxygen in the air to produce ozone, the most toxic component of the form of pollution commonly known as smog. Ozone attacks lung tissue, and is very injurious, even in very low concentrations. To prevent the formation excessive levels of ozone, the VOC content of paint, and its conditions.

Lead in house paint is a problem only if it is damaged or disturbed. Paint in good condition that is not flaking or chalking, or is covered by well-maintained lead free paint is not a hazard in itself. Lead can also be a hazard when it is on surfaces subject to friction or impact such as windows and doors, or on railings where children can chew it. High concentrations of lead found in garden soils in older residential areas can be due to residue from lead-based paint.

Lead-based paint is most likely to be found on window frames, doors, skirting boards, kitchen and bathroom cupboards, exterior walls, gutters, metal surfaces and fascias. It can also be found on interior walls, ceilings and areas with enamel paint. Pink and red primer both contain lead, so you should think twice before disturbing any surface which has had any of these paints applied.

The main environmental impacts associated with paint come from the manufacturer of the components, rather than manufacturing of the product itself.

\section{Titanium Dioxide}

By far the greatest environmental impact is derived from the manufacture of Titanium Dioxide ( $\mathrm{TiO} 2)$ :

- High embodied energy (54-76 MJ/kg) 9 .

- Emissions during manufacture including (depending on process) CO2, N2O, SO2, NOx $\mathrm{CH} 4$ and VOCs 9.

- A number of waste streams, including spent acid and metal sulfates, emanate from the manufacturing process, each of which carries an environmental impact. A number of EU directives seek to reduce and eliminate the pollution caused.

- Raw materials are derived from scarce resources. 


\section{Coloured pigments}

The environmental impacts associated with coloured pigments are various - though not as intense in their effects as those for Titanium Dioxide. It is worth noting too, that although there are 'natural' and 'man-made' pigments, not all 'natural' pigments have a lesser impact than man-made. Specifiers are recommended to examine closely the claims made by the manufacturer.

\section{VOCs and Ozone}

Ozone produced as part of human activities is a pollutant and a constituent of smog. Ozone is formed when nitrogen oxides, carbon monoxide and VOCs react in the atmosphere in the presence of sunlight.

Although lead has been banned for use in paint for decades, other chemicals commonly found in paint have also been linked with significant health and environmental issues.

Most paints and stains contain volatile organic compounds (VOCs) and other chemicals that create toxic fumes that can linger indoors for long periods of time. Some VOCs contribute to ozone depletion while others have known health risks. One of the chemicals linked to illness is propane sulfone, which is widely used in paints and is a powerful known carcinogen. The respiratory system and skin are the most significant routes for poisoning from chemicals in paints and stains. The good news is that low-VOC or no-VOC paints and stains are becoming more widely available to the consumer. See our list of products below for some examples.

If you must use products containing toxic chemicals, do so only in well-ventilated areas and avoid prolonged exposure. Do not allow children to sleep or play in newly painted rooms until the smell has completely dissipated.

\section{CONCLUSION}

The best guidance for usability of paint is:

1. Specify water-based paint with low titanium oxide content together with low quantities of binder.

2. Avoid paints with high levels of organic solvents - though this is becoming increasingly easy thanks to the effects legislation.

3. Further reduce health concerns by careful study of lists of ingredients where available and the comparing of chemicals to databases of toxins.

4. Where ingredients are not published, it might be fair to assume that there is a reluctance by the manufacturer to disclose - in which case it might be wise to avoid that product altogether.

5. When renovating or doing maintenance that could disturb old paint, care must be taken to avoid exposing yourself, your family, your neighbors or your pets to lead residues.

\section{REFERENCES}

1. Exposures in the Painting Trades and Paint Manufacturing Industry and Risk of Cancer Among Men and Women in Sweden - Brown, Linda et al, published in the Journal of Occupational and Environmental Medicine: March 2002

2. Household Exposure to Paint and Petroleum Solvents, Chromosomal Translocations, and the Risk of Childhood Leukemia - Scélo, Metayer et al, Univ California, 2009 Association of domestic exposure to volatile organic compounds with asthma in young children - Rumchev et al, Curtin University of Technology, Perth

3. Indoor Residential Chemical Emissions as Risk Factors for Respiratory and Allergic Effects in Children: a Review - Mark J. Mendell, Lawrence Berkeley National Laboratory, 
$\begin{array}{lllll}\text { published in } \quad \text { Indoor } & \text { Air } & \text { Journal, }\end{array}$ IARC Monographs on the evaluation of carcinogenic risks to humans 1999, 73-16, 307-27

4. http://www.resene.co.nz/whatispaint.htm

5. http://www.pollutionissues.co.uk/how-paint-pollution-effects-environment.html

6. http://www.hercenter.org/facilitiesandgrounds/paints.cfm

7. http://www.greenspec.co.uk/building-design/paint/

8. http://grassrootsinfo.org/common-exposures/paints-stains/

9. http://www.environment.gov.au/protection/chemicals-management/lead/lead-in-housepaint

10. http://www.greenspec.co.uk/building-design/paint/

11. https://answers.yahoo.com/question/index?qid $=20071109135443 \mathrm{AA} 4 \mathrm{kkHz}$

12. http://www.ukmarinesac.org.uk/activities/recreation/r03_03.htm

13. http://www.lead.org.au/lanv1n2/lanv1n2-8.html 